\title{
Personal Motivational Factors to Aligning Innovation Culture: Evidence on Trenggalek, East Java, Indonesia
}

\author{
Moeljadi Moeljadi ${ }^{1 *}$, Triningsih Sri Supriyati ${ }^{2}$, Sherlinda Octa Yuniarsa ${ }^{1}$ \\ ${ }^{1}$ Department of Management, Faculty of Economics and Business, University of Brawijaya, \\ Jl. MT. Haryono 165, Malang 65145, Indonesia \\ ${ }^{2}$ Faculty of Economics and Business, University of Muhammadiyah Malang, Jl. Raya Tlogo Mas, \\ No. 246, Malang 65144, Indonesia
}

\begin{abstract}
Society of Trenggalek has a team, strength, and excellent entrepreneurial support by personal motivational. Many different teams format have been used in good organization for short-term and long-term condition. To gain benefits, teams must be successful embedded within the organization. It must carefully and systematic development, management, and alignment for teams. Because it means for individual engagement and team performance to growth up like batik, food, and others. An success of processed by products from the beginning to be able to trade and through offline and online. In addition, good organizations also give rise to good agreement and also to make joint decisions. This study are used qualitative methods with surveys and interviews. The results of this study proved that this research involved an important role in fostering the awareness of societies for development and independence, through industrial development which gave rise to the best entrepreneurs. So, a value of empowered cross-functional teams to drive such programs has not been lost to the majority of government in Trenggalek like culture.
\end{abstract}

Keywords: Creativity, cultural capital, entrepreneur, innovation, motivation

\section{Introduction}

Innovation should be supported by innovative people. They tend to know how to organize company's innovation performance in terms of specific business targets. This research continues a characteristic of innovative firms before further examining the different firm (individual investor, hierarchical firms, and Silicon Valley firms) that can be used for examining very different business challenges. After that a high-level view of how firms might competitively position themselves to meet their innovation goals, go on to examine internal structures can be used to drive innovation.

After reviewing, some basic aspects of teams, they discuss how teams can be structured to support innovation. This attracted a significant amount of research, particularly in the

*Corresponding author: sherlindaocta33@gmail.com 
interface between Resource and Development for marketing and Resource Development for manufacturing.

A new challenge being faced in the market that societies with different culture are relying less on co-located teams, and more on virtual or global teams [1]. Many aspects of these types for teams are developed and discussed very good results. So, individual roles and leadership in innovation by elaboration where and how they fit into a entrepreneur's product development framework. Eventually, the role of important thing for team leaders in directing teams and make a key decisions and product champions in guiding innovation project through hurdles and challenges of innovation are also presented.

In this research, what makes a personal creative for example in managing a company in line with goals for business achievement and evaluating critical ideas of organization communication. These entrepreneurs promote based on selection and promotion individuals on particular achievement. In this situation, supervisors (personal motivational) tend to be taking responsibility for evaluating work in short-term performance assignment. Every individual should produce positive results. Administrative capability determines promotions based on the individual task, empowerment, or individual freedom in such highly directive environment.

Eventually, leader tends to shape organizational culture by signaling that an important thing about values for organization and good priorities [2]. Leaders are expected to prepare and support teams concerning entrepreneurs, innovation, and value added. Generally, leadership is very important to expectation for performance and provide a center like incubator and to growth a new idea. They also reinforce a culture by using symbols in defining work and giving several characters such as capable to growth up in industry 4.0. So, a leader can break for vision to more excellence down into discrete tasks; and it can communicate to every member carefully. Because it more challenges outside, so we must be able to create and innovate for the best superior products, for example from livestock, agriculture, and design for fashion

\section{Theoretical frameworks}

Besides that, characteristics of creativity companies is different in how they manage and organize their specific innovation strategies. Mueller [3] pointed out that some organization types are developed to support innovation in several ways.

\subsection{Organizations structures for innovation}

The definition of organization structure based on centralization and formalization. Centralization talks about the consolidation of specific action, and or functional boundaries within an organization. Meanwhile, formalization tends to explain an extent of roles, responsibilities, and integration in achieving formal roles and managing procedures. Also, a literature regarding innovation is not final definition. Sometimes, centralization might facilitate creativity of innovative moment by decreasing conflict and leading uniform response to transformation. It will be solved by allowing ideas exchanges which familiarize employees with changes in the status quo and decreases associated uncertainty. 


\subsection{Integration key functions in innovation}

Cross functional co-operation facilities completion of projects on schedule, within budget and with fewer design changes. It can stimulate maximum creativity levels than only working in isolation experience and also increase the possibility of product development successfully. For many different functions may be involved within an innovation project, the core functions are Resource and Development or engineering (to create), manufacturing (to make), and marketing (to market). An effective integration between these functions has attracted a significant amount or research attention, most of which suggests a positive correlation to innovation performance.

\subsection{Teams and innovation}

Teams are key in developing innovation vision. At any level, teams are very important especially at corporate, product division, research project and development. Generally, it is formed under team-work to overcome individual and provide collective solution. Logic of team is simple based on combination every member about their perspectives and solution related to a problem, and it will be a dynamic exchange and intercommunication among its members. Therefore, a cross-functional program team is most common approach to develop innovation project successfully [4].

\subsection{Team structures for innovation}

Autonomous cross functional teams operating in a matrix organization have been found to be a successful format from amongst all other team alternatives [5]. It uses of traditional functional organizations produces the lowest success in controlling cost, meeting schedules, achieving technical performance and overall results [6]. A value of empowered cross functional teams to drive such as programs has not been lost to the majority of companies.

\subsection{Social capital and cultural capital}

Social capital is a possession form including contacts and acquaintances in common society. Economic capital (material possession) and cultural capital (education, welldeveloped) is part of social capital in general. It drives individuals into several social classes. Social capital can be seen at the collective level, community, or locality [7]. Also, it is something impersonal and enables determining actions. In this points, social code develops on the level of collective, which drives specific social activities less costly regarding transactions. However, the society does not only happen on the collective level but also on the individual level.

\section{Methodology}

This research uses a qualitative method and case study approach. It is because case study follows into explanatory, exploratory, and descriptive case studies. A case study substance can be explored in depth research. [8]. However, this research aims to explore how many societies in Trenggalek can sets a goal and drives for achievement ideas and innovation to an organization. An extent to discuss for critical information that identified, collected, communication, and also creativity. For other case, the important place for generate and evaluation for the next ideas of product, then a way about individualism and involvement is nurtured as part of a human relations and drives for motivation between personal and teams in the Trenggalek areas. 
This research is used primary data to be obtained by interviews with informants are selected. Interviews also describe about conversations with a specific purpose. This research used four criterias: credibility, dependability, confirmability, and transferability, because of inspection techniques for implementation qualitative research.

\section{Results}

\subsection{Innovation and creativity to goals}

The long-term goals of innovative society emphasize on activity and creativity in every team collaboration. Teams open considerable freedom of speech in the organization to obtain clearly strategic goal. Organizations has the short-term profit because of less innovative ideas in teamwork. It tends to be afraid taking risks, as a consequences, it exert tight control a business. Tighter control often has a problem on creating efficient operations to fulfill functional objectives.

\subsection{Creativity of organization to external environment}

Highly creative organization is not only being responsive and efficient to external environment but also effective in good response others [9]. It can be achieved by increasing sources of information and knowledge regarding an ideal picture of organization. Not surprisingly, it will encourage new ideas and support creative innovation. Generally speaking, these ideas are evaluated in a manner of balances for inquisitive exploration and acceleration of purposes. In contrast, less creative organization means less innovative ideas or great resistance its system.

\subsection{Teams characteristics and satisfaction}

Highly creative organization respects for individualism value and diversity of opinions [10]. The results of highly creative organizations come from a significant point of view their employess. The value of consensus is not only an expense of opinion diversity in their employess, but also regarding thinking, behaviour, or actions. Employee has a equal position but it still under control. Hence, it provide individual considerable to define and finish their tasks. Therefore, it helps individual's work satisfaction throught achievement and recognition from a company.

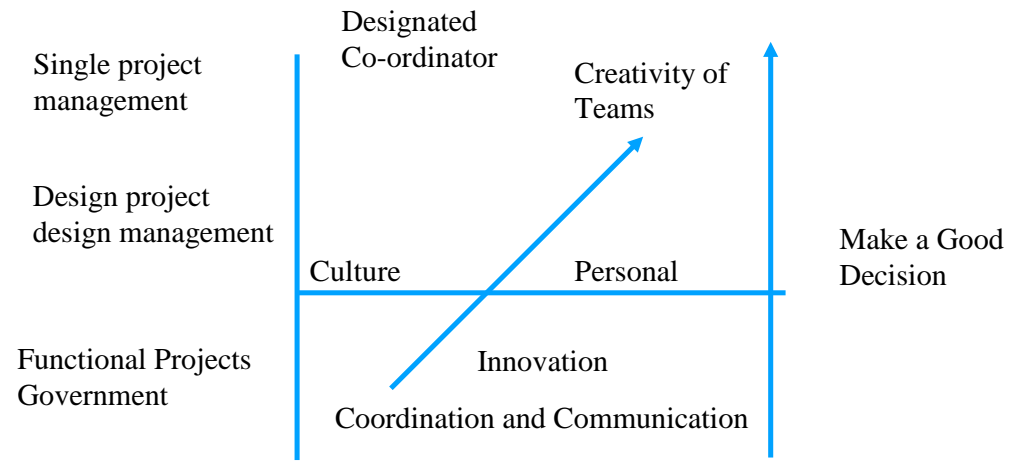

Fig. 1. Teams, empowerment, and effectiveness 
After reviewing the different types such as how organizations might be structed internally to reckon with novelty. After briefly dealing with common structures such as functional, matrix, and other. How to develop the functional integration necessary to underpin the cross-functional challenge of managing inventiveness. A key of issue covered is how to create alignment between marketing, Resource and Development, and manufacturing. However, cross-functional integration is not a magic bullet to meet all innovation challenges. Consequently, both the advantages and drawbacks of integration and looked at how integration and involvement might change move to the innovation process like make and sell batik Trenggalek by offline or online.

Eventually, moving down a level in aggregation, the use of teams in executing innovation projects. Cross-functional teams are the cornerstone of most innovation frameworks and structure innovation, then elaborated in detail. As societies or team become global in their performance have dealt by developing global or virtual teams. The challenges of global team forms were presented because of survive with other people to share many knowledgeable about culture, language, and maybe tourism place in Trenggalek. Besides teams, government can use other structures to drive innovation with different pattern. It is including research laboratories, incubator entrepreneurship, and tiger teams. The leadership qualities exhibited in one role closely mirrored. The extended role of the sociocultural as a review board member, particularly in the context of decision making between societies in Trenggalek to growth up together.

The implementation of economic concept in regional development should consider cultural factors and social relation. It can be identified by understanding social problems in Trenggalek related to personal and social motivational. In this case, people should identify themselves with the model of integrated by local identity and endogenous regional development. Local business should be developed as potential project of regional development, which it is connected with the local value and also it ensures an existence of rules in the local community. Furthermore, it can help people to deal with social issues, especially non-material (social and cultural) hidden potentiality. Strengthening participation in developing regions reflects the local interest and increases social-cultural capital. Therefore, it is possible to prevent negative impacts between personal between personal motivational and innovation culture in Trenggalek.

\section{Conclusion}

In conclusion, this research has shown how organizations are structured to address their innovation challenges and how the progressive decomposition of the organizations or teams into departments, groups, and individuals demands. It is based on carefully consideration from everyone with a view that the entrepreneur is to innovate successfully by cultural growth.

\section{References}

1. A.I. Mockaitis, L. Zander, H.D. Cieri, The International Journal of Human Resource Management, 29,14:1-22(2018). https://doi.org/10.1080/09585192.2018.1428722

2. A.I. Miladi, International Strategic Management Review, 2,1:21-30(2014). https://doi.org/10.1016/j.ism.2014.03.002

3. D.C. Mueller, The Oxford Handbook of Capitalism. New York: Oxford University Press (2012). https://www.oxfordhandbooks.com/view/10.1093/oxfordhb/ 9780195391176.001.0001/oxfordhb-9780195391176 
4. T. Kono, S. Clegg, Trends in Japaness Management: Continuing Strengths, Current Problems and Changing Priorities. New York: Palgrave MacMillan (2001). https://www.palgrave.com/gp/book/9780333929704

5. L. Copuš, H. Saajgalíková, E. Wojćák. Procedia Manufacturing, 32:360-367(2019). https://doi.org/10.1016/j.promfg.2019.02.226.

6. S.H. Aschehoug, E. Lodgaard, K.Ǿ. Schulte, Procedia CIRP, 84:1107-1111(2019). https://www.sciencedirect.com/science/article/pii/S2212827119309266

7. A. Mazzucchelli, R. Chierici, T. Abbate, S. Fontana, Technological Forecasting and Social Change, 146:242-252(2019).

https://www.sciencedirect.com/journal/technological-forecasting-and-socialchange/vol/146/suppl/C

8. R. Yin, Case Study Research: Design and Methods. CA: Sage Publications Beverly Hills (2009). https://www.researchgate.net/publication/200465328

Case Study Research_Design_Methods

9. A. Baregheh, J. Rowley, S. Sambrook, Management Decision, 47,8:1323-1339(2009). https://www.emeraldinsight.com/doi/abs/10.1108/00251740910984578

10. N. Anderson, K. Potočnik, J. Zhou, Journal of Management, 40,5:1297-1333(2014). https://journals.sagepub.com/doi/abs/ 10.1177/0149206314527128 